\title{
An EPQ inventory model considering an imperfect production system with probabilistic demand and collaborative approach
}

\author{
Katherinne Salas-Navarro, Jaime Acevedo-Chedid, Gina Mora Árquez, Whady F. Florez, Holman \\ Ospina-Mateus, Shib Sankar Sana, Leopoldo Eduardo Cárdenas-Barrón
}

DOI: $\underline{\text { http://doi.org/10.1108/JAMR-07-2019-0141 }}$

\begin{abstract}
:
Purpose

The purpose of this paper is to propose an economic production quantity (EPQ) inventory model considering imperfect items and probabilistic demand for a two-echelon supply chain. The production process is imperfect and the imperfect quality items are removed from the lot size. The demand rate of the inventory system is random and follows an exponential probability density function and the demand of the retailers is depending on the initiatives of the sales team.
\end{abstract}

Design/methodology/approach

Two approaches are examined. In the non-collaborative approach, any member of the supply chain can be the leader and takes decisions to optimize the profits, and in the collaborative system, all members make joint decisions about the production, supply, sales and inventory to optimize the profits of the supply chain members. The calculus approach is applied to find the maximum profit related to the members of the supply chain.

Findings

A numerical example is presented to illustrate the performance of the EPQ model. The results show that collaborative approach generates greater profits to the supply chain and the market's demand represents the variable behavior and uncertainty that is generated in the replenishment of a supply chain.

Originality/value

The new and major contributions of this research are: the inventory model considers demand for products is random variable which follows an exponential probability distribution function and it also depends on the initiatives of sales teams, the imperfect production system generates 
defective items, different cycle time are considered in manufacturer and retailers and collaborative and non-collaborative approaches are also studied.

Keywords: Optimization, Supply chain, Inventory, EPQ model, Probabilistic demand 